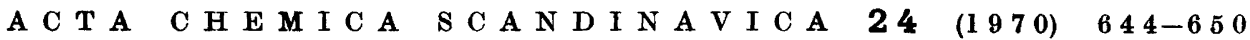

\title{
Gas Chromatographic Determination of Chlorinated Acetyl Chlorides and Phosgene Present in Air in Very Low Concentrations
}

\author{
JAN ANDERS DAHLBERG and INGER BIRGITTA KIHLMAN
}

The Chemical Laboratory, Uddeholms AB, S-663 00 Skoghall, Sweden

\begin{abstract}
A gas chromatographic method has been developed for the determination of mono-, di-, and trichloroacetyl chloride at low concentration levels in air. The acyl chloride vapour in a small air sample (about 1 litre) is absorbed in 2-propanol and the ester then formed is determined gas chromatographically with electron capture detection. By this method the di- and trichloroderivatives at concentrations lower than $1 \mathrm{ppm}$ may be measured. For monochloroacetyl chloride the sensitivity is somewhat less.

It has also been confirmed that phosgene may be determined down to $10^{-3} \mathrm{ppm}$ in air using gas chromatography and electron capture detection.
\end{abstract}

T ow boiling chlorinated hydrocarbons, e.g. tri- and perchloroethylene, give $\mathcal{L}_{\text {on }}$ thermal oxidation mainly hydrogen chloride ${ }^{1}$ and on photochemical oxidation chloroacetyl chlorides ${ }^{2}$ as chlorine containing products. In both cases some phosgene is also formed. Being used extensively for dry cleaning and degreasing purposes chlorinated solvents are sometimes not protected from contacts with hot surfaces or from exposure to ultraviolet light and thus hazardous concentrations of phosgene and chloroacetyl chlorides may occur, e.g. in workshops where degreasing and welding are going on simultaneously. As the threshold limit value (TLV) of phosgene is very low $(0.1 \mathrm{ppm}$ proposed by Am. Conf. Gov. Industrial Hygienists 1966) and as TLV's of the chlorinated acetyl chlorides are lacking, the need for sensitive analytical procedures to determine these substances is obvious. A satisfactory method should not only be able to detect and roughly determine the total amount of acyl chlorides (including phosgene) but should also be able to separate a mixture of the substances which may be present in the sample.

older methods. Specific and sensitive methods have not been described for the determination of chlorinated acetyl chlorides. For acyl chlorides in general their great reactivity towards amines such as aniline, morpholine or hydroxyl- 
amine is often utilized., ${ }^{3,4}$ After having been transformed to amides acyl chlorides may also be determined by gas chromatography. ${ }^{5}$ Direct gas chromatographic separation of acyl chlorides and bromides on a preparative scale has also been reported. ${ }^{6}$ Likewise aliphatic acyl chlorides have been determined by means of esterification and gas chromatography of the esters. ${ }^{7}$ Gas chromatography combined with electron capture detection would thus be a solution to the separation and sensitivity problems in our case.

A method for determination of phosgene on sub-toxic levels in air by means of gas chromatography and electron capture detection has been reported by Priestley and co-workers. ${ }^{8}$ On the other hand Linch et al. ${ }^{9}$ state that reliable results cannot be obtained at concentrations below $100 \mathrm{ppm}$ even when the electron affinity detector is used. Some confirmation of Priestley's method would therefore be worthwhile.

\section{EXPERIMENTAL}

Separation of acetyl chlorides. At first direct separation of monochloroacetyl chloride (MCAC), dichloroacetyl chloride (DCAC) and trichloroacetyl chloride (TCAC) together with tri- and perchloroethylene in liquid mixtures was tried on several stationary phases, namely silicon oil DC-200, fluorosilicon oil FS 1265, Apiezon L, Kel-F grease, diethyleneglycol succinate polyester, tricresylphosphate and tridecyl phthalate. The best separations were obtained by means of silicon oil DC 200 and tridecyl phthalate on Chromosorb W. When trying to separate the acetyl chlorides and the chlorinated hydrocarbons from air samples, where these substances were present in ppm concentrations, we did, however, never get any peaks from the acetyl chlorides. Different tube materials (stainless steel, glass, teflon) and different supports (kieselguhr, glass beads and teflon) were tried, all with negative results in spite of using the very sensitive electron capture detector. A probable explanation seems to be some reaction between the acyl chloride and the column material, so we tried to make this hypothetical reaction complete by feeding the columns with large amounts of acetyl chlorides. However, this treatment also was unsuccessful. Therefore we tried the indirect method of esterifying the acetyl chlorides by absorption in alcohol and gas chromatographic determination of the esters formed.

Determination of isopropyl esters of chloroacetic acids. The following gas chromatographic conditions were chosen:

Apparatus. Perkin Elmer 800 with EC-detector; column, $20 \%$ silicon oil DC 200 on Chromosorb $\mathrm{W}$ in a stainless steel tube, diam. 1/8", length $2 \mathrm{~m}$; column and detector temp., $120^{\circ} \mathrm{C}$; injection, $3 \mu \mathrm{l}$ on column; carrier gas, Ar with $5 \% \mathrm{CH}_{4}(30 \mathrm{ml} / \mathrm{min}$ through column $+210 \mathrm{ml} / \mathrm{min}$ dilution gas after column); detector voltage, $0.8 \mu \mathrm{s}$ pulses of $40 \mathrm{~V}$, frequency $10 \mathrm{kc} / \mathrm{s}$.

The stationary phase was chosen to give the lowest possible reduction of the standing current from the detector. 2-Propanol and isopropyl esters turned out to be more easily separated than the corresponding methyl or ethyl compounds. Fig. 1 shows a chromatogram with the peaks of 2-propanol, trichloroethylene, perchloroethylene and the isopropyl esters of mono-, di-, and trichloroacetic acid.

If the method is to be used in cases when phosgene may be present one might expect peaks of alcoholysis products of this substance [iPrOCOCl and (iPrO) ${ }_{2} \mathrm{CO}$ ] to disturb the gas chromatogram. In fact two peaks appear, but they do not coincide with the peaks of the esters of the chloroacetic acids (the second one has almost the same retention time as trichloroethylene) and furthermore the electron capture detector is rather insensitive to these substances. This is evident from Fig. 2, which shows a chromatogram of a solution of $2.5 \mathrm{ml}$ pure phosgene gas in $10 \mathrm{ml}$ 2-propanol.

Solutions of the esters in known concentrations in the alcohol were used for the calibration. There is some uncertainty regarding the best way of plotting electron capture peak data vs. concentration. According to the original theory of Lovelock, Beer's law should be valid, that is $-\ln (1-h / i)=k[\mathrm{~A}]$, where $h$ is the peak height, $i$ is the standing current and $[\mathrm{A}]$ is the concentration of the substance to be determined in the sample. (The partial pressure of $A$ at peak maximum is assumed to be proportional to [A]). On

Acta Chem. Scand. 24 (1970) No. 2 


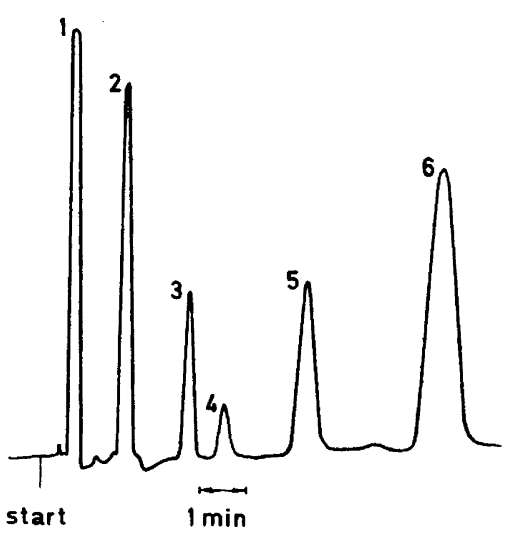

Fig. 1. Gas chromatogram showing peaks of the following compounds: 1, 2-Propanol (solvent); 2, Trichloroethylene (33 ppm by volume); 3, Perchloroethylene (0.33 ppm); 4, iPr-MCA (33 ppm); 5, iPr-DCA (10 ppm); 6, iPr-TCA (10 ppm).

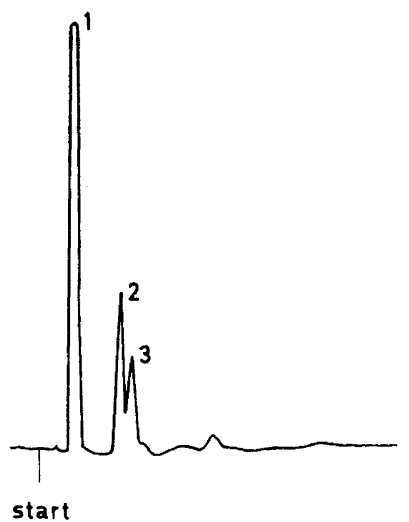

Fig. 2. Gas chromatogram of a solution of $2.5 \mathrm{ml}$ pure phosgene gas in $10 \mathrm{ml} 2$ propanol. Peak 1, 2-propanol; peaks 2 and 3 , phosgene products.

the other hand Wentworth and Chen ${ }^{10}$ from a kinetic model with 4 different electron absorption mechanisms have derived an equation, that should better describe the relation between the peak height and the concentration provided that pulse technique with low frequency is applied. With our notation this relation should read $h /(i-h)=k[\mathbf{A}]$.

In Fig. 3 data from some calibration runs have been plotted. It seems evident from this figure that regarding the DCA and TCA esters the function $h /(i-h)$ is proportional to the concentration within a somewhat larger interval than the function $\ln (1-h / i)$.

The gas chromatographic error has been studied regarding the determination of isopropyl dichloroacetate (iPr-DCA). Table 1 shows standard deviations, $S$, at different

Table 1.

\begin{tabular}{|c|c|c|c|}
\hline $\begin{array}{c}\text { iPr-DCA } \\
\text { ppm by volume }\end{array}$ & \begin{tabular}{c} 
Degrees of $_{\text {freedom }^{a}}$ \\
\hline 0.1
\end{tabular} & $\begin{array}{c}h /(i-h) \\
(\text { mean })\end{array}$ & $\begin{array}{c}\mathbf{S} \\
\% \text { of } h /(i-h)\end{array}$ \\
\hline 1.0 & 6 & 0.0074 & 9.6 \\
3.0 & 26 & 0.057 & 6.5 \\
10.0 & 9 & 0.173 & 5.2 \\
\hline
\end{tabular}

a Number of degrees of freedom=(number of determinations):2.

concentration levels of the ester in 2-propanol. $S$ has been calculated by combination of variances for a number of duplicates. The increase in $\mathbf{S}$ caused by lowering of the concentration from 10 to $0.1 \mathrm{ppm}$ should probably be due to disturbances in the standing current. Such disturbances evidently will be more perceptible at lower concentrations when the attenuation has to be reduced. 
Alcoholysis of acyl chlorides. If the method is to be useful in air pollution studies acyl chlorides present even in very low concentrations must be quantitatively transformed into esters in 2-propanol. To test this condition solutions of MCAC, DCAC, and TCAC $(100 \mathrm{ppm})$ in hexane were diluted with 2-propanol to $10 \mathrm{ppm}$ (MCAC) and $1 \mathrm{ppm}$ (DCAC and TCAC), respectively. The diluted solutions were analysed by gas chromatography after about $10 \mathrm{~min}$. Provided the water content of the alcohol was below $0.1 \%$ all the acyl

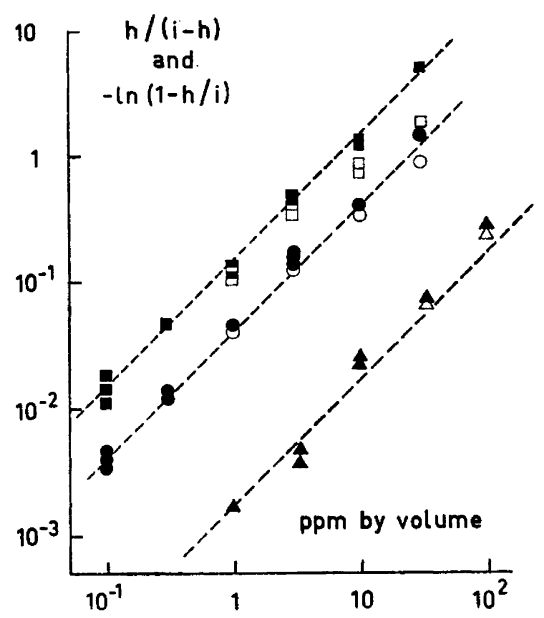

Fig. 3. Calibration graph of isopropyl esters of MCA, DCA and TCA. $\square$ iPr-TCA; O iPr-DCA; $\triangle \triangle$ iPr-MCA. Filled symbols, $h /(i-h)$; unfilled symbols, $-\ln (1-h / i)$; - - lines with theoretical slope.

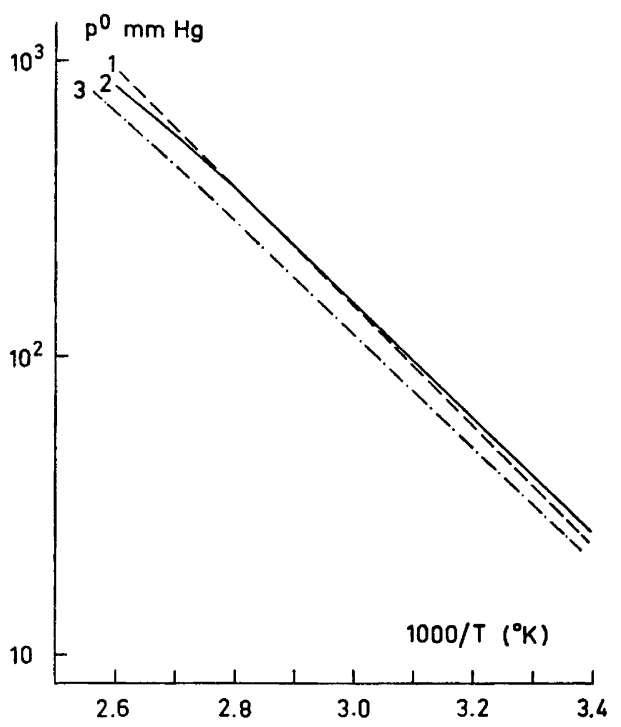

Fig. 4. Vapour pressure curves of chloroacetyl chlorides. (Filed data from this laboratory.) Curve 1, MCAC; curve 2, DCAC; curve 3, TCAC.

chloride charged was recovered, within experimental error, as the corresponding ester. If the water content was increased to about $1 \%$, the yield of the ester was only about $50 \%$ after $24 \mathrm{~h}$ (tested with DCAC only). Evidently the hydrolysis of the acetyl chlorides is much more rapid than the alcoholysis, and, moreover, the uncatalysed esterification of the acid is very slow.* Thus it is necessary to use 2-propanol practically free of water. The possibility of reducing the requirement of low water content by means of an esterification catalyst has not been tried.

Absorption of acyl chlorides from the air. For testing of different absorption methods mixtures of air and the acetyl chlorides were made by flow dilution of air saturated with an acetyl chloride vapour at a certain temperature. The equipment comprised two flow meters, a train of washing flasks, containing the acetyl chloride and a dilution chamber into which the saturated air stream and the diluting stream were fed through the same inlet. The apparatus was an all-glass one, except for the connection between the saturating and the dilution vessels, which was a narrow teflon tubing. As the volume of the

* The following experiment was performed: A solution at the start containing $4.70 \%$ DCA in 2-propanol was kept at ambient temperature for 15 days. After this time $4.49 \%$ DCA was recovered as free acid. During the same time the water content increased from $0.13 \%$ to $0.16 \%$.

Acta Chem. Scand. 24 (1970) No. 2 
dilution air $\left(V_{\mathrm{d}} 1 / \mathrm{h}\right)$ was at least 200 times the volume through the saturating vessels $(V$ l/h) and as the pressure drop between the flow meters and the outlet of the dilution chamber was at most $10 \mathrm{~mm} \mathrm{Hg}$ the partial pressure of the acyl chloride in the mixture leaving the dilution chamber could reasonably be approximated by

$$
p=p_{0} \quad V \times 10^{6} /\left(B-p_{0}\right) V_{\mathrm{d}} \mu \mathrm{atm}
$$

In this equation $p_{0}$ is the vapour pressure of the acyl chloride and $B$ is the barometric pressure. The vapour pressure of MCAC, DCAC, and TCAC as a function of temperature is shown in Fig. 4.

From the outlet of the dilution vessel a branch stream was fed through an all-glass tubing to the absorption apparatus to be tested. Plastic materials (e.g. teflon, viton) could not be used in this part of the equipment because of very strong sorption of the acetyl chlorides. Different kinds of absorption vessels were tested. With regard to the amount of 2-propanol a train of 4 washing flasks of the type shown in Fig. 5 proved to be most effective. With $2 \mathrm{ml} 2$-propanol in each of these flasks practically total absorp. tion was obtained. From the chromatogram the partial pressure of an acetyl chloride in an air sample was calculated by the formula:

$$
p=a V_{1} d R T / M \quad V_{\mathrm{g}}
$$

where $a=$ the content of the corresponding isopropyl ester (ppm by volume) in the 2-propanol used at the sampling; $V_{1}=$ the volume of 2-propanol used at the sampling (ml); $V_{\mathrm{g}}=$ the volume (l) of air passed through the sampling vessels; $d=$ density of the ester $(\mathrm{g} / \mathrm{ml})\left(d_{4}{ }^{20}=1.0888\right.$ for iPr-MCA, 1.2053 for iPr-DCA and 1.3034 for iPr-TCA $\left.{ }^{11}\right)$; $\mathbf{M}=$ molecular weight of the ester.

Conditions and results from absorption tests with different acyl chlorides are shown in Table 2.

\begin{tabular}{|c|c|c|c|c|c|c|c|}
\hline \multirow{2}{*}{$\begin{array}{l}\text { Com- } \\
\text { pound }\end{array}$} & \multirow{2}{*}{$\begin{array}{c}\text { Number } \\
\text { of absorp- } \\
\text { tion } \\
\text { flasks }\end{array}$} & \multirow{2}{*}{$\begin{array}{c}V_{1} \\
(\mathrm{ml})\end{array}$} & \multirow{2}{*}{$\begin{array}{l}V_{\mathrm{g}} \\
(\mathrm{l})^{\mathrm{s}}\end{array}$} & \multirow{2}{*}{$\begin{array}{c}\text { Absorp- } \\
\text { tion } \\
\text { time } \\
\text { (min) }\end{array}$} & \multicolumn{3}{|c|}{$p(\mu \mathrm{atm})$} \\
\hline & & & & & $\begin{array}{c}\text { Calculated } \\
\text { eqn. } 1\end{array}$ & $\begin{array}{l}\text { Found } \\
\text { eqn. } 2\end{array}$ & $\begin{array}{l}\text { Dif- } \\
\text { ference }\end{array}$ \\
\hline DCAC & 2 & 4 & 0.177 & 31 & 2.3 & 1.4 & -0.9 \\
\hline DCAC & $\overrightarrow{3}$ & $\overline{6}$ & 0.195 & 30 & 2.1 & 2.0 & -0.1 \\
\hline DCAC & 4 & 8 & 0.220 & 40 & 2.3 & 2.3 & 0 \\
\hline DCAC & 4 & 8 & 0.293 & 45 & 1.8 & 1.8 & 0 \\
\hline DCAC & 4 & 8 & 0.232 & 15 & 3.9 & 3.8 & -0.1 \\
\hline DCAC & 4 & 8 & 3.00 & 2.4 & 40 & 37 & -3 \\
\hline DCAC & 4 & 8 & 3.00 & 2.3 & 39 & 35 & -4 \\
\hline MCAC & 4 & 8 & 0.650 & 31 & 34 & 36 & +2 \\
\hline TCAC & 4 & 8 & 0.289 & 15 & 4.5 & 4.7 & +0.2 \\
\hline
\end{tabular}

Table 2.

Evidently the value predicted by eqn. 1 and the measured value (eqn. 2) are in good agreement when at least four absorption steps are used. The flow rate at the sampling may be varied within quite wide limits without risking intolerable errors. With as high a flow rate as about $1 \mathrm{l} / \mathrm{min}$ the experimental error is just slightly higher than the standard deviation of the gas chromatographic determination of the corresponding esters. 


\section{Phosgene determination}

Mixtures of phosgene and air were prepared using the same method as in the case of the chlorinated acetyl chlorides. In the phosgene case two successive dilution steps had to be involved in the equipment in order to reach concentrations far below $1 \mathrm{ppm}$. Vapour pressure data were taken from the literature. ${ }^{12}$ The following gas chromatographic conditions were chosen.

Apparatus. Perkin Elmer 800 with EC-detector; column, $20 \%$ silicon oil DC 200 on Chromosorb W in a stainless steel tube, diam. 1/8", length $2 \mathrm{~m}$; column temperature,

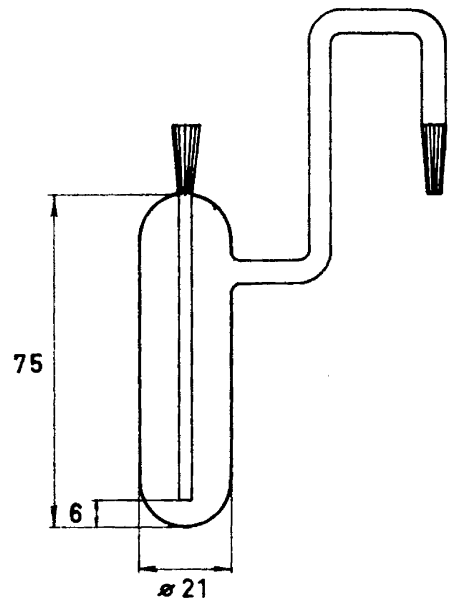

Fig. 5. Vessel for absorption of chloroacetyl chlorides from air.

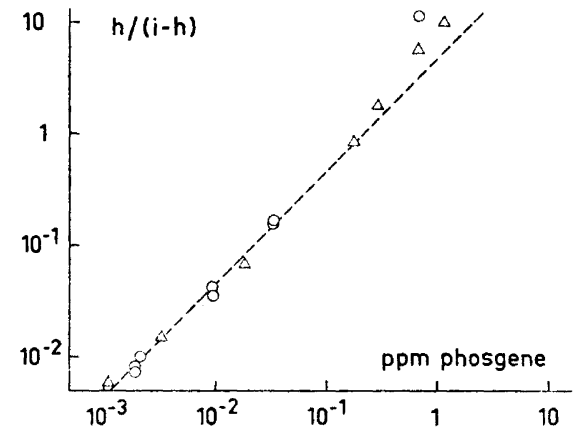

Fig. 6. Phosgene calibration graph: $\triangle$ Measurements 5 Oct. 1965; O measurements 12 Nov. 1965; - - line with theoretical slope.

$25^{\circ} \mathrm{C}$; detector temperature, $120^{\circ} \mathrm{C}$; injection, $1 \mathrm{ml}$ with gas tight syringe on column; carrier gas, Ar with $5 \% \mathrm{CH}_{4}(30 \mathrm{ml} / \mathrm{min}$ through column $+210 \mathrm{ml} / \mathrm{min}$ dilution gas after column $)$; detector voltage, $0.8 \mu \mathrm{s}$ pulses of $40 \mathrm{~V}$, frequence $10 \mathrm{kc} / \mathrm{s}$.

With these conditions the retention times of oxygen and phosgene were about 28 and $130 \mathrm{sec}$, respectively. Trichloroethylene is eluted after about $30 \mathrm{~min}$.

For charging the sample to the column we first tried a gas sampling valve of a type normally used in conjunction with our instrument. However, by this method we did not obtain constant peak heights when trying to inject constant amounts of the sample. With a gas sampling syringe (Hamilton), made gas tight by means of teflon tape wound round the plunger, we got much better results. The injection error was $2.4 \%$ (the standard deviation of 37 injections). To allow quantitative analysis of phosgene the column filling had to be treated with acyl chlorides, e.g. acetyl chloride. Otherwise the phosgene seemed to be consumed in the column. The treatment may be done in the column by feeding this with fairly large samples of acetyl chloride. Fig. 6 shows a calibration graph. The method allowed detection of phosgene well below $10^{-3} \mathrm{ppm}$. As is evident from the graph the conditions chosen are not suitable for determination of phosgene above 0.1 ppm level. However, this could easily be done by increasing the frequency of the pulses on the detector; e.g., by changing the frequency from $10 \mathrm{kc} / \mathrm{s}$ to $100 \mathrm{kc} / \mathrm{s}$ the sensitivity of the detector became about 10 times lower. (Cf. Lovelock ${ }^{13}$ ). 


\section{CONCLUSIONS}

The isopropyl esters of MCA, DCA, and TCA can be simultaneously determined in mixture with tri- and perchloroethylene in 2-propanol solution using gas chromatography and electron capture detection. The method can also be applied to the determination of the three chloroacetyl chlorides. The sampling procedure described above is recommended if the chloroacetyl chlorides are present in air in very low concentrations. As the electron capture detector is sensitive enough for an approximate determination of $10^{-11} \mathrm{~mole} / \mu \mathrm{l}$ iPr-MCA and $10^{-12}$ mole/ $\mu \mathrm{l}$ iPr-DCA or iPr-TCA, concentrations of the order of $1 \mathrm{ppm}$ or lower for the di- and trichloroderivatives may be measured in air pollution studies despite using small samples ( $\sim 1$ litre). As the acetyl chlorides, on sampling, are converted immediately into less reactive species the sample solution need not necessarily be analysed at once, and thus there is no need for chromatographic equipment at the sampling site. The presence of phosgene does not disturb the determination of MCAC, DCAC, and TCAC, nor does trichloroethylene or perchloroethylene, and the method can thus be used for the study of the oxidative decomposition of vapours of chlorinated hydrocarbons, which might occur in workshops or industrial areas. The whole procedure (sampling + gas chromatography) may be performed in less than one hour.

Regarding the phosgene determination this work has confirmed the results of Priestley and co-workers, that gas chromatography combined with electron capture detection makes measurements of the concentration of this gas down to $10^{-3} \mathrm{ppm}$ (by volume) possible.

The authors wish to thank Miss L. Myrin and Miss L. Norenius for experimental assistance and Dr. John S. Davidson for revising the English. The work has been sponsored by the Swedish Board for Technical Development, the Swedish Medical Research Council and Uddeholms $A B$.

\section{REFERENCES}

1. Sjöberg, B. Svensk Kem. Tidskr. 64 (1952) 63.

2. Dahlberg, J. A. Acta Chem. Scand. 23 (1969) 3081.

3. See, e.g., Hogsett et al. Anal. Chem. 25 (1953) 1207.

4. Godder, R. F. et al. Anal. Chem. 27 (1955) 1251.

5. Hishta, C. and Bomstein, J. Anal. Chem. 35 (1963) 65.

6. Feairheller, Jr., W. R. and Evers, R. L. J. Gas Chromatog. 5 (1967) 585.

7. Simonaitis, R. A. and Guvernator, III, G.C. J. Gas Chromatog. 5 (1967) 527.

8. Priestley, Jr., L. J., Critchfield, F. E., Ketcham, N. H. and Cavender, J. D. Anal. Chem. 37 (1965) 70.

9. Linch, A. L., Lord, Jr., S. S., Kubitz, K. A. and de Brunner, M. R. Am. Ind. Hyg. Assoc. J. 26 (1965) 465.

10. Wentworth, W. E. and Chen, E. J. Gas Chromatog. 5 (1967) 170.

11. Beilstein, 4. Aufl., 3. Erg.w., Band II, 1. Teil, pp. 442, 459 and 471.

12. Giauque, W. F. and Jones, W. M. J. Am. Chem. Soc. 70 (1948) 120.

13. Lovelock, J. E. Anal. Chem. 35 (1963) 474.

Received August 28, 1969. 